\title{
Regulation by the Medial Amygdala of Copulation and Medial Preoptic Dopamine Release
}

\author{
Juan Dominguez, Jon V. Riolo, Zhujian Xu, and Elaine M. Hull \\ Department of Psychology, State University of New York at Buffalo, Buffalo, New York 14260-4110
}

The medial preoptic area (MPOA) is a critical integrative site for male copulatory behavior in most vertebrate species. Extracellular dopamine (DA) is increased in the MPOA of male rats immediately before and during copulation. DA agonists microinjected into the MPOA of male rats facilitate and DA antagonists inhibit sexual behavior. A major source of input to the MPOA is the medial amygdala (MeA), which processes and relays olfactory information to the MPOA. We now report that microinjections of a DA agonist into the MPOA of animals with excitotoxic lesions of the amygdala restored copulatory ability that was lost after the lesions. Moreover, radio-frequency lesions of the MeA impaired copulation and blocked the increases in extracellular DA seen in animals with sham lesions during exposure to a receptive female and during copulation. Thus, both copulatory ability and the MPOA DA response, during exposure to a receptive female and during copulation, are facilitated by input from the MeA to the MPOA.

Key words: medial preoptic area; medial amygdala; dopamine; male rats; sexual behavior; apomorphine; microdialysis; HPLC-EC
The medial preoptic area (MPOA) plays an important role in the regulation of male sexual behavior. Damage to the MPOA impairs sexual behavior (Klaric and Hendricks, 1986; de Jonge et al., 1989; Liu et al., 1997; Paredes et al., 1998), whereas stimulation of the MPOA enhances behavior (Malsbury, 1971; Paredes et al., 1990; Rodriguez-Manzo et al., 2000). The neurotransmitter dopamine (DA) facilitates sexual behavior in a number of species, including rats and humans (for review, see Bitran and Hull, 1987; Melis and Argiolas, 1995). The MPOA is one site in which DA may promote sexual behavior (for review, see Hull, 1995). DA agonists microinjected into the MPOA facilitate sexual behavior (Hull et al., 1986; Pehek et al., 1988a, 1989; Scaletta and Hull, 1990; Markowski et al., 1994), whereas microinjections of a DA antagonist impair copulation, genital reflexes, and sexual motivation (Pehek et al., 1988b; Warner et al., 1991). Moreover, extracellular DA increases in the MPOA of male rats during precopulatory exposure to an estrous female and during copulation compared with baseline (Hull et al., 1995).

One major source of input to the MPOA is the medial amygdala (MeA). The MeA receives sensory information from the olfactory bulbs and vomeronasal organ, processes it, and relays it to the MPOA and other sites (for review, see Kostarczyk, 1986; Wood, 1997). The MeA is important for male sexual behavior (for review, see Meisel and Sachs, 1994; Newman, 1999), because damage to the corticomedial amygdala leads to impairment of sexual behavior (Giantonio et al., 1970; Harris and Sachs, 1975; Kondo, 1992; McGregor and Herbert, 1992; Kondo and Yamanouchi, 1995; Heeb and Yahr, 2000). Exposure to an inaccessible estrous female increases noncontact erections (Kondo et al., 1999) and facilitates subsequent copulation (de Jonge et al., 1992) in males with sham lesions but not in those with MeA lesions;

Received July 17, 2000; revised Oct. 18, 2000; accepted Oct. 20, 2000.

This research was supported by National Institutes of Health Grant MH40826 to E.M.H. We thank Richard Davis for assisting with surgeries in experiment 1.

Correspondence should be addressed to Dr. Elaine M. Hull, Department of Psychology, State University of New York at Buffalo, Buffalo, NY 14260. E-mail: emhull@acsu.buffalo.edu.

Copyright (C) 2001 Society for Neuroscience 0270-6474/01/210349-07\$15.00/0 thus, the MeA also facilitates the response to and assimilation of sexually exciting stimuli. Finally, sexual activity increases Fos immunoreactivity, indicating an increase of cellular activity in both the MeA and MPOA of male rats (Robertson et al., 1991; Baum and Everitt, 1992; Coolen et al., 1996; Heeb and Yahr, 1996; Veening and Coolen, 1998).

Together, the aforementioned studies confirm the importance of the MeA and the MPOA in the regulation of male sexual behavior. However, the effects of MeA lesions on mating-induced dopamine activity in the MPOA have not been explored previously. The present experiments were designed to test the following: (1) whether microinjections of a classic dopamine $D_{1} / D_{2}$ receptor agonist (apomorphine) into the MPOA would reverse the inhibitory effects of amygdala lesions on copulation; and (2) whether lesions of the MeA would attenuate extracellular dopamine release in the MPOA of male rats during basal conditions, in response to a female, and during copulation.

\section{MATERIALS AND METHODS}

Subjects

Adult male Long-Evans/Blue Spruce rats (Harlan Sprague Dawley, Indianapolis, IN) were housed individually in large plastic cages. Rats were housed in a climate-controlled room, on a 14/10 hr light/dark cycle, with lights off at 11:00 A.M. and on at 9:00 P.M. Food and water were available ad libitum.

\section{Stimulus females}

Female rats of the same strain were ovariectomized under ketamine hydrochloride $(50 \mathrm{mg} / \mathrm{kg})$ and xylazine hydrochloride $(4 \mathrm{mg} / \mathrm{kg})$ anesthesia. Females were brought into behavioral estrus with $10 \mu \mathrm{g}$ of estradiol benzoate at $48 \mathrm{hr}$ before and $500 \mu \mathrm{g}$ of progesterone at $4 \mathrm{hr}$ before they were used as stimulus females. Behavioral receptivity was confirmed by placing the female with a stud male shortly before they were to be used in an experiment. All procedures were in accordance with the National Institutes of Health Guidelines for the Use of Animals and were approved by the local Institutional Animal Care and Use Committee.

\section{Experiment 1}

Stereotaxic surgery. Fourteen sexually experienced animals $(\sim 300 \mathrm{gm}$ at the time of surgery) underwent surgeries for lesions of the $\operatorname{MeA}(n=9)$ 
or sham lesions $(n=5)$ and received guide cannula implants for microinjections. Animals were anesthetized with ketamine hydrochloride (50 $\mathrm{mg} / \mathrm{kg}$ ) and xylazine hydrochloride $(4 \mathrm{mg} / \mathrm{kg})$. They then received bilateral lesions of the MeA by microinjection of ibotenic acid (Research Biochemicals, Natick, MA) in a phosphate buffer solution $(10 \mu \mathrm{g} / \mu \mathrm{l})$. Microinjections of ibotenic acid or vehicle were done using a $1 \mathrm{ml}$ gas-tight syringe on a Harvard Apparatus (South Natick, MA) infusion pump (model 22). Polyethylene tubing (PE-20; Becton Dickinson, Sparks, MD) was attached, on opposite ends, to the syringe and a 27 gauge injection cannula, $30 \mathrm{~mm}$ in length. The injection cannula and the portion of tubing attached to it were filled with ibotenic acid solution; the syringe and the portion of tubing attached to it were filled with water; an air bubble separated the two. The injection cannula was attached to a cannula holder, and the outlet portion of the injection cannula was lowered into the brain $(2 \mathrm{~mm}$ per $60 \mathrm{sec})$, ending above the MeA [anteroposterior (AP), $-0.8 \mathrm{~mm}$; mediolateral (ML), $\pm 3.5 \mathrm{~mm}$; dorsoventral (DV), $-8.5 \mathrm{~mm}$; according to Pellegrino et al. (1979)]. Flow rate was then set to $0.25 \mu \mathrm{l} / \mathrm{min}$, and the solution was injected for $3 \mathrm{~min}$. After injection, the injection cannula was left in place for an additional $5 \mathrm{~min}$ before withdrawal. For later injection of apomorphine, the animals also received guide cannula implants, made of 23 gauge thin-wall stainless steel tubing. The guide cannula ended $2 \mathrm{~mm}$ above the MPOA [AP, 2.3 $\mathrm{mm}$; ML, $0.3 \mathrm{~mm}$; DV, $-6.2 \mathrm{~mm}$; according to Pellegrino et al. (1979)] and were secured to the skull and skull screws with dental acrylic. Upon completion, bacitracin $(400 \mathrm{U} / \mathrm{gm})$ antibiotic was spread around the wound margins, and the animal was injected with gentamicin antibiotic $(0.02 \mathrm{mg} / \mathrm{kg})$. An obturator, cut the same length as the guide cannula, was then inserted into the guide cannula until the microinjection experiment began. Aseptic techniques were used throughout all surgical procedures.

Microinjections and drugs. Apomorphine (Research Biochemicals) was dissolved in vehicle $(1 \mu \mathrm{g} / \mu \mathrm{l})$ immediately before microinjection. The vehicle was isotonic saline with $0.2 \%$ ascorbic acid. Microinjections were performed in a counterbalanced manner, wherein all animals received microinjections of vehicle or of $0.5 \mu \mathrm{g}$ apomorphine into the MPOA, on each of two weekly tests.

Apomorphine or vehicle was injected using a $1 \mathrm{ml}$ gas-tight syringe on a Harvard Apparatus (model 22) infusion pump. PE-20 tubing was attached, on opposite ends, to the syringe and a 27 gauge injection cannula, $17 \mathrm{~mm}$ in length. Before injecting the solution, the metal obturator was removed and replaced with the injection cannula. Microinjections were administered over a 1 min interval, followed by an additional $1 \mathrm{~min}$ with the injection cannula left in place. The injection cannula was then replaced with the obturator; the male was returned to his home cage and taken to another room for behavioral testing.

Behavioral tests. All subject males were sexually experienced; they received sexual experience by copulating for $1 \mathrm{hr}$ or until the first ejaculation. Males failing to ejaculate in the first session were allowed to copulate for $1 \mathrm{hr}, 2 \mathrm{~d}$ later. All animals successfully ejaculated by the end of the second session. Two days after sexual experience, preoperative behavioral measures were obtained; $2 \mathrm{~d}$ later animals received surgeries. Surgery was followed by a 2 week recovery period; after the recovery period, postoperative behavioral measures were obtained. Two days after obtaining postoperative measures, microinjections of vehicle or drug were administered and immediately followed by behavioral testing; 2 d later, animals received the opposite treatment before a second behavioral test.

Behavioral measures were obtained by observing the subject male copulate with a receptive female in his home cage. An experimenter who was blind to the treatment groups of the animals made observations. Animals were allowed to copulate for $30 \mathrm{~min}$ after the first intromission, or if no intromissions occurred, for $30 \mathrm{~min}$ after introduction of the female. The following measures were recorded during the preoperative, postoperative, and microinjection behavioral tests: mount latency [latency to first mount, or first intromission if not preceded by a mount (ML)]; intromission latency [latency to the first intromission (IL)]; ejaculation latency [latency from the first intromission to the first ejaculation (EL)]; postejaculatory interval [interval from ejaculation to the ensuing intromission (PEI)]; mount frequency and intromission frequency [number of mounts and intromissions preceding the first ejaculation (MF and IF)]; intromission ratio $\left[\mathrm{IF} /(\mathrm{IF}+\mathrm{MF})\right.$, preceding the first ejaculation, $\left.\mathrm{IR}_{1}\right]$; and ejaculation frequency during the $30 \mathrm{~min}$ test (EF).

Histology and data analysis. After all behavioral tests were completed, cannula and lesion placements were verified histologically. Animals were deeply anesthetized with sodium pentobarbital, and, using the same procedure as that used for drug microinjection, a $0.5 \mu \mathrm{l}$ dye solution was injected into the MPOA. The animals were immediately killed, and their brains were removed, frozen, and sliced $(40 \mu \mathrm{m})$ using a cryostat. Brain slices including the amygdala were mounted on slides and exposed to a cresyl violet staining solution. Brain slices including the MPOA were mounted on slides and examined for cannula placement using a projection magnifier.

All data were analyzed using the SigmaStat computer program, version 1.0 (SPSS, Chicago, IL). In experiments 1 and 2, two-factor repeated measures (RM) ANOVA tests were used, followed by one-factor analysis if the two-factor analyses indicated a significant main effect of treatment. Newman-Keuls tests were used to probe for significant differences among individual means. Also, $t$ tests were used in experiment 2 to probe for differences in behavioral measures between animals with sham or MeA lesions.

\section{Experiment 2}

Stereotaxic surgery. Twenty-five sexually experienced animals $(\sim 300 \mathrm{gm}$ at the time of surgery) received either MeA lesions $(n=13)$ or sham lesions $(n=12)$ and received guide cannulas for microdialysis. Animals underwent a surgical procedure similar to that in experiment 1 ; however, because of the inconsistency and large size of excitotoxic lesions in experiment 1 , radio-frequency lesions were used in experiment 2. Lesions were made using a TCZ electrode (Radionics, Burlington, MA), which was lowered to end in the MeA [AP, $-3.2 \mathrm{~mm}$; ML, $\pm 3.2 \mathrm{~mm}$; DV, $-8.8 \mathrm{~mm}$; according to Paxinos and Watson (1998)]. Using an RFG-4A radio-frequency lesion generator (Radionics), the temperature surrounding the tip $(0.25 \mathrm{~mm})$ of the TCZ electrode was raised to and maintained at $+80^{\circ} \mathrm{C}$ for $60 \mathrm{sec}$. Animals in experiment 2 also received guide cannula implants, similar to those in experiment 1 , but for microdialysis probe placement. Before implanting the guide cannula in the MPOA, the incisor bar was raised to $+5.0 \mathrm{~mm}$ from the interaural line, and coordinates for the MPOA (AP, $2.3 \mathrm{~mm}$; ML, $0.3 \mathrm{~mm}$; DV, $-6.2 \mathrm{~mm}$ ) were obtained according to Pellegrino et al. (1979).

Histology and data analysis. A procedure similar to that in experiment 1 was used for histological analyses in experiment 2. However, instead of an injection cannula to inject the dye, a microdialysis probe was used.

Microdialysis procedures. Concentric microdialysis probes were constructed according to the procedure of Yamamoto and Pehek (1990). The dialysis membrane (Spectra/Por in vivo microdialysis hollow fibers; Spectrum, Gardena, CA) had an outer diameter of $170 \mu \mathrm{m}$, an inner diameter of $150 \mu \mathrm{m}$, an active dialyzing length of $1 \mathrm{~mm}$, and an 18,000 molecular weight cutoff. A Teflon-covered tether encased the inflow tubing. Dulbecco's PBS (in mM: $138 \mathrm{NaCl}, 2.7 \mathrm{KCl}, 0.5 \mathrm{MgCl}_{2}, 1.5 \mathrm{KH}_{2} \mathrm{PO}_{4}$, and 1.2 $\mathrm{CaCl}_{2}, \mathrm{pH}$ 6.8, filtered and degassed before use; Sigma, St. Louis, MO) was perfused at a rate of $0.5 \mu \mathrm{l} / \mathrm{min}$ with a Harvard Apparatus (model 22) infusion pump, using a $1 \mathrm{ml}$ gas-tight syringe. Samples were collected every $6 \mathrm{~min}$, immediately frozen $\left(-80^{\circ} \mathrm{C}\right)$, and later assayed using HPLC with electrochemical detection (HPLC-EC).

Behavioral tests. After probes were implanted, the subject was returned to his home cage, and the probe was then attached to the perfusion line. Five hours later, four baseline samples were collected. A sexually receptive female was then placed, in a mesh cage $(12.5 \times 26 \times 15 \mathrm{~cm})$, above the male's home cage, where the male could see, smell, and hear the female but could not copulate with her (precopulation period). During the precopulation period, four dialysis samples were collected. After precopulation, the female was placed into the male's home cage, where they could copulate; during this period, five additional samples were collected, and behavioral observations were recorded. After the fifth sample was collected, and if the male was not in a PEI, the female was removed and 2 final samples were collected (postcopulation period). If the male was in PEI, the test was extended until he intromitted, after which the female was removed. The following samples were assayed using the HPLC-EC: the last three baselines, the first precopulation sample, the first three copulation samples, and the second postcopulation sample.

Chromatography. The LC Packings (San Francisco, CA) chromatographic system consisted of an Acurate microflow processor and pulse damper, a Valco injector with a $500 \mathrm{nl}$ sample loop, and an Antec microelectrochemical detector, equipped with a microflow cell ( $11 \mathrm{nl}$ cell volume), with a glassy carbon working electrode and a $\mathrm{Ag} / \mathrm{AgCl}$ reference electrode. The analytical column was an LC Packings Fusica reversed-phase capillary column $(300 \mu \mathrm{m}$ inner diameter, $5 \mathrm{~cm}$ long, packed with $3 \mu \mathrm{m} \mathrm{C}-18$ particles). The working electrode was maintained at an applied potential of $+0.8 \mathrm{~V}$ relative to the reference electrode. A 

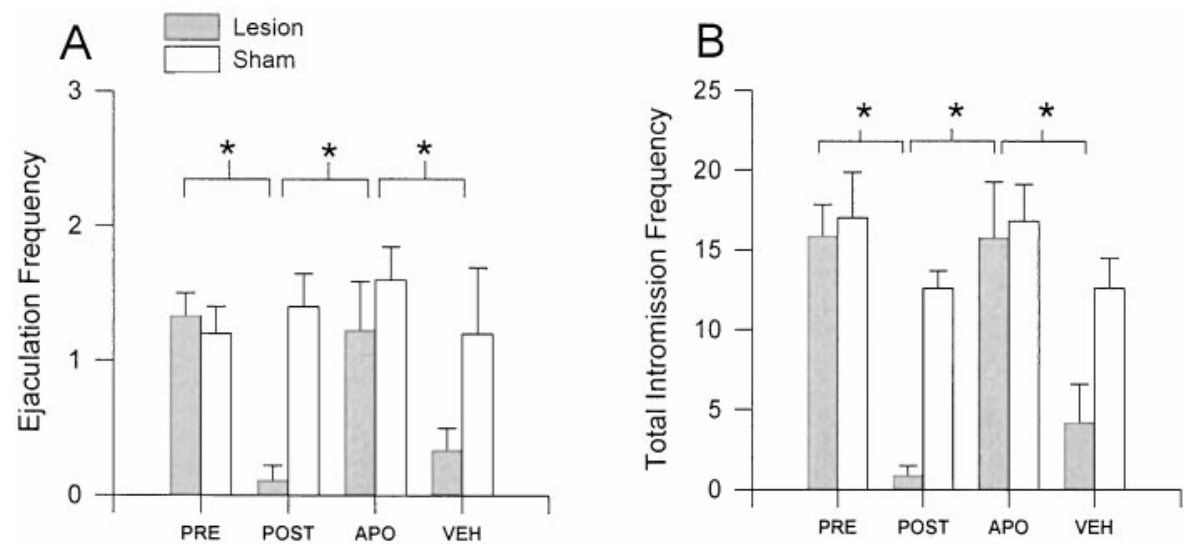

Figure 1. $A, B$, Ejaculation frequency and total intromission frequency for animals with amygdala lesions or sham lesions in experiment 1 . There were no significant differences in ejaculation frequency or total intromission frequency for animals with sham lesions. Animals with amygdala lesions displayed significantly fewer ejaculations and fewer total intromissions after surgery (POST) compared with before surgery (PRE). Microinjections of apomorphine $(A P O)$, but not vehicle $(V E H)$, restored measures of copulation for animals with amygdala lesions. Values are expressed as mean $\pm \operatorname{SEM}\left({ }^{*} p<0.05\right)$.

Gilson Medical Electronics (Middleton, WI) pump (model 307) delivered mobile phase through the system at $0.5 \mathrm{ml} / \mathrm{min}$; however, the Acurate microflow processor split the flow, so that flow through the analytical column was $\sim 7 \mu \mathrm{l} / \mathrm{min}$. The mobile phase consisted of $32 \mathrm{~mm}$ citric acid, $54.3 \mathrm{~mm}$ sodium acetate, $0.074 \mathrm{~mm}$ EDTA, $0.215 \mathrm{~mm}$ octyl sulfonic acid (Fluka, Milwaukee, WI), and 4\% methanol (v/v). It was filtered and degassed under vacuum; $\mathrm{pH}$ was 3.45 . Data were collected using an IBM-compatible computer, running Gilson Medical Electronics Unipoint system controller software, which also controlled the pump parameters.

\section{RESULTS}

\section{Experiment 1: MeA lesions severely inhibited copulation, which was restored by apomorphine in the MPOA}

A two-factor RM-ANOVA revealed a significant difference attributable to treatment $\left(F_{(1,36)}=6.69 ; p<0.03\right)$ for ejaculation frequency (Fig. $1 A$ ). A one-factor ANOVA showed that animals receiving sham lesions did not display significant changes in ejaculation frequency after surgery or after microinjections. However, for animals with amygdala lesions, a one-factor ANOVA $\left(F_{(3,24)}=6.98 ; p<0.002\right)$ revealed significant differences attributable to treatment, such that the number of ejaculations in the postoperative test was lower than in the preoperative and the apomorphine tests $(p<0.05)$. There was not a significant difference between numbers of ejaculations in the preoperative and apomorphine tests. However, animals with amygdala lesions achieved more ejaculations when they received apomorphine than when they received saline $(p<0.05)$. Microinjections of vehicle into the MPOA of animals with amygdala lesions did not restore copulation when compared with postoperative measures.

Because only one animal in the lesion group ejaculated during postoperative testing, we are unable to perform statistical analyses on latencies or mount and intromission frequencies preceding the first ejaculation. A two-factor RM-ANOVA revealed a significant difference attributable to treatment $\left(F_{(1,36)}=8.50 ; p<0.02\right)$ for total intromission frequency [total number of intromissions in the test $\left.\left(\mathrm{IF}_{\mathrm{T}}\right)\right]$ (Fig. $\left.1 B\right)$. A one-factor ANOVA showed that animals receiving sham lesions did not display significant changes in $\mathrm{IF}_{\mathrm{T}}$ after surgery or after microinjections. However, for animals with amygdala lesions, a one-factor $\operatorname{ANOVA}\left(F_{(3,24)}=11.2\right.$; $p<0.001)$ revealed significant differences attributable to treatment, such that $\mathrm{IF}_{\mathrm{T}}$ in the postoperative test was lower than in the preoperative and apomorphine tests $(p<0.05)$. In addition, animals with amygdala lesions displayed more intromissions for the entire test when they received apomorphine than when they received saline $(p<0.05)$. Analysis with a two-factor RMANOVA revealed no changes in total mount frequency.

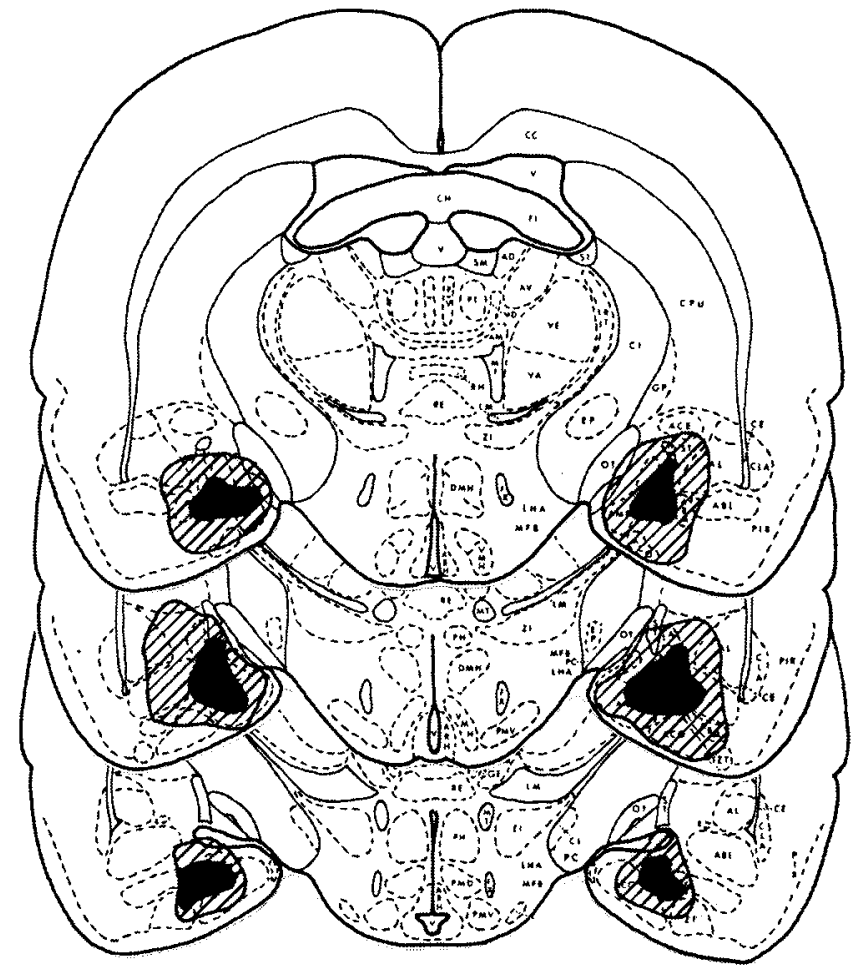

Figure 2. Representative perimeters of smallest lesion (black) and largest lesion (dash) for animals with ibotenic lesions of the amygdala in experiment 1 . Coordinates for this figure are (top to bottom) from bregma $-0.2,-0.8$, and $-1.2 \mathrm{~mm}$, drawn from Pellegrino et al. (1979).

Histological analysis revealed that all animals received microinjections ending in the MPOA. Analysis of lesions revealed that, in addition to the MeA, animals also received partial or total lesion of the cortical, central, lateral, and basal amygdala (Fig. 2).

\section{Experiment 2: MeA lesions impaired copulation and blocked the MPOA DA increase in response to a female and during copulation}

In experiment 2, analyses of behavioral measures using a $t$ test revealed significant differences in behavior for animals with sham lesions and MeA lesions. Compared with animals with sham lesions, animals with MeA lesions did the following: displayed significantly fewer ejaculations $\left(t_{(23)}=5.69 ; p<0.001\right)$ (Fig. $3 A$ ); required more intromissions to achieve the first ejaculation $\left(t_{(22)}\right.$ $=4.04 ; p<0.001$ ) (Fig. $3 B)$; required more time to reach an ejaculation $\left(t_{(22)}=-3.11 ; p<0.01\right)($ Fig. $3 C)$; and required more 

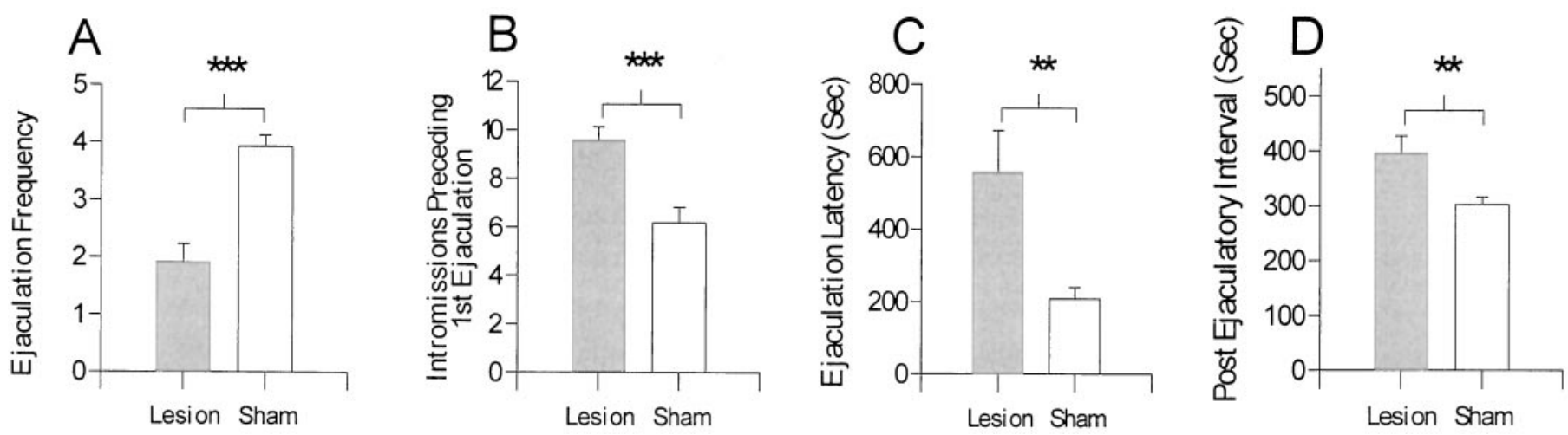

Figure 3. $A-D$, Behavioral measures obtained from animals with MeA lesions or sham lesions in experiment 2. $A$, Ejaculation frequency; $B$, the number of intromissions preceding the first ejaculation; $C$, latency to the first ejaculation, after the first intromission; and $D$, the postejaculatory interval. MeA lesions impaired most measures of copulation. Values are expressed as mean $\pm \operatorname{SEM}\left({ }^{* *} p<0.01 ;{ }^{* * *} p<0.001\right)$.

time to achieve an intromission after an ejaculation $\left(\mathrm{PEI} ; t_{(22)}=\right.$ 2.88; $p<0.01$ ) (Fig. 3D). The apparent increase in ML (sham, $14.5 \pm 5.09 \mathrm{sec}$; MeA lesion, $32.2 \pm 9.71 \mathrm{sec} ; t_{(22)}=-1.48 ; p=$ 0.15 ) and IL (sham, $20.6 \pm 5.46 \mathrm{sec}$; MeA lesion, $59.4 \pm 22.26 \mathrm{sec}$; $t_{(22)}=-1.69 ; p=0.10$ ) for animals with MeA lesions were not statistically significant. Analyses of $\mathrm{IR}_{1}$ preceding the first ejaculation revealed no significant differences $\left(t_{(22)}=0.80 ; p=0.43\right)$ between animals with sham lesions and those with MeA lesions

DA concentrations in dialysis samples collected during baseline were not significantly different in the lesion versus sham groups (MeA lesion, $0.533 \pm 0.05 \mathrm{pg} / \mu \mathrm{l}$; sham lesion, $0.598 \pm 0.04 \mathrm{pg} / \mu \mathrm{l}$; $\left.t_{(13)}=0.87 ; p=0.39\right)$. Analyses of percent changes from baseline, with a two-factor RM-ANOVA, revealed significant differences attributable to treatment $\left(F_{(1,95)}=9.11 ; p<0.01\right)$, sample $\left(F_{(5,95)}\right.$ $=5.20 ; p<0.001)$, and interaction $\left(F_{(5,95)}=3.85 ; p<0.005\right)$ (Fig. 4). Newman-Keuls tests revealed that animals with sham lesions had larger increases in extracellular DA than did animals with MeA lesions $(p<0.05)$. A one-factor ANOVA $\left(F_{(5,50)}=6.27\right.$; $p<0.001)$ for the sham group revealed increases in extracellular DA during precopulation and copulation intervals; animals with MeA lesions showed no increases from baseline.

Histological analysis revealed that all animals received probe placements ending in the MPOA. Analyses of lesions revealed that 11 of 13 animals undergoing lesion surgeries received lesions of the MeA. Of the 11 lesions, most were centered in the posterior region of the $\mathrm{MeA}$; however, three extended into the intraamygdaloid division of the bed nucleus of the stria terminalis and into the posteroventral portion of the amygdala; one lesion also extended into the basomedial amygdala and the optic tract (Fig. 5). Analyses of lesions also revealed bilateral differences in lesion size; lesions on the animal's right side appeared larger than lesions on the left. Of the 11 lesions, one was a unilateral lesion; however, post hoc analysis of the animal's behavioral data revealed that his measures were consistent with those of animals receiving bilateral lesions. Of the 13 animals receiving surgery for MeA lesions, two did not show lesions on either side of the MeA; their behavioral and chromatography data were analyzed with those of animals receiving sham lesions.

\section{DISCUSSION}

In experiment 1 , lesions of the amygdala significantly decreased $\mathrm{EF}$ and $\mathrm{IF}_{\mathrm{T}}$. Microinjections of apomorphine, but not vehicle, into the MPOA of animals with amygdala lesions restored cop-

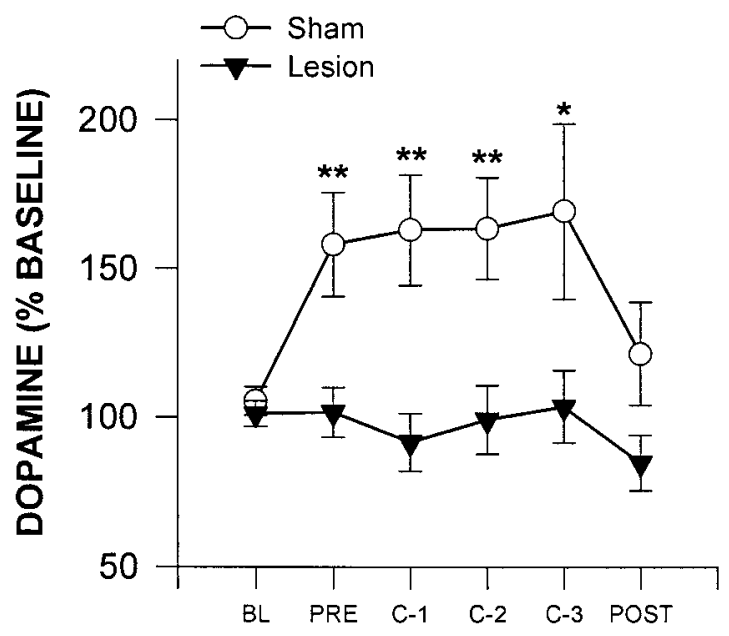

SAMPLE PERIOD

Figure 4. Levels of DA in dialysate from the MPOA of animals with MeA lesions or sham lesions. Levels represent percent changes from baseline $(B L)$ in response to precopulatory exposure to an estrous female $(P R E)$ during copulation $(C 1-C 3)$ and after copulation $(P O S T)$. Extracellular levels of DA significantly increased during the precopulatory and copulatory stages of testing for animals with sham lesions but not for animals with MeA lesions. The baseline value used for computation was obtained by dividing the value of the last baseline by the mean of all three baselines. Values are expressed as mean $\pm \operatorname{SEM}\left({ }^{*} p<0.05 ;{ }^{* *} p<0.01\right)$.

ulation. Measures of copulation did not change for animals receiving sham lesions.

In experiment 2, lesions of the MeA significantly decreased ejaculation frequency, increased ejaculation latency, increased the number of intromissions preceding the first ejaculation, and increased the PEI compared with sham lesions. Moreover, analyses of microdialysis samples, collected during exposure to an estrous female and during copulation, showed a significant response of extracellular DA in the MPOA of animals with sham lesions but not in animals with MeA lesions compared with baseline.

Several studies have emphasized the role of the MeA and the MPOA in sexual behavior. For example, stimulation of the MPOA facilitated copulation (Malsbury, 1971; Paredes et al., 1990; Rodriguez-Manzo et al., 2000), whereas lesions of the MPOA (Klaric and Hendricks, 1986; de Jonge et al., 1989; Liu et al., 1997; Paredes et al., 1998) or the MeA (Giantonio et al., 1970; 


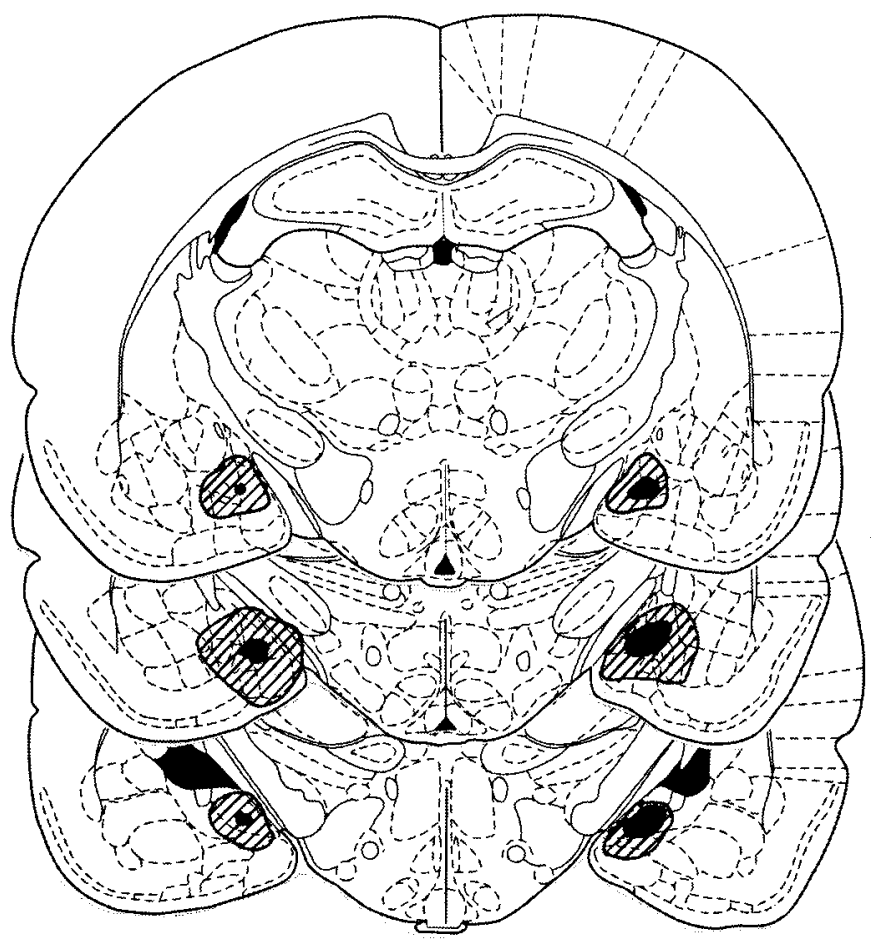

Figure 5. Representative perimeters of smallest lesion (black) and largest lesion (dash) for animals with radio-frequency lesions of the MeA in experiment 2 . The lateral ventricle and the dorsal third ventricle are also black. Most lesions were similar to the smallest lesion depicted above. Coordinates for this figure are (top to bottom) from bregma $-2.56,-3.14$, and $-3.60 \mathrm{~mm}$, drawn from Paxinos and Watson (1998).

Harris and Sachs, 1975; Kondo, 1992; McGregor and Herbert, 1992; Kondo and Yamanouchi, 1995; Heeb and Yahr, 2000) impaired copulation. DA in the MPOA is especially important for copulation, because microinjections of a DA agonist into the MPOA facilitated copulation (Hull et al., 1986; Pehek et al., 1988a, 1989; Scaletta and Hull, 1990; Markowski et al., 1994), and microinjections of an antagonist impaired copulation, ex copula genital reflexes, and sexual motivation (Pehek et al., 1988b; Warner et al., 1991). In addition, DA levels in the MPOA of male rats increased while in the presence of a sexually exciting stimulus and during copulation (Hull et al., 1995).

Immunohistochemical studies have investigated whether activation of cells in the MeA and MPOA are correlated with sexual activity. Cellular activity, measured by Fos immunoreactivity, in both the MeA and MPOA increased after copulation (Robertson et al., 1991; Baum and Everitt, 1992; Coolen et al., 1996; Heeb and Yahr, 1996; Veening and Coolen, 1998). Moreover, experiments using Fos immunohistochemistry coupled with tract tracing techniques have shown that neurons in the posterodorsal MeA (MeApd) that project to the medial preoptic nucleus were activated after sexual behavior, especially for animals that had ejaculated (Coolen et al., 1998). In the present study, lesions of the MeA impaired copulation and attenuated mating-induced DA activity in the MPOA. These results further support the importance of the MeA for sexual behavior and suggest that one means through which the amygdala facilitates copulation is by increasing DA levels in the MPOA immediately before and during copulation.

Lesions in experiment 1 nearly abolished copulation; these results are more dramatic than those in previous studies examin- ing the behavioral effects of MeA lesions (for review, see Meisel and Sachs, 1994). One possible explanation is that lesions in experiment 1 were larger than expected and frequently included the entire amygdala. Nevertheless, microinjections of apomorphine restored intromission and ejaculation frequencies for animals with amygdala lesions. This finding suggests that the amygdala facilitates copulation by increasing DA activity in the MPOA. Alternatively, it is possible that enhancement of copulation by apomorphine, seen in animals with amygdala lesions, offset a nondopaminergic effect in the MPOA or elsewhere. Therefore, in experiment 2, we measured mating-induced DA activity in the MPOA of animals with MeA lesions or sham lesions.

Because of the inconsistency of excitotoxic lesions in experiment 1 , radio-frequency lesions were used in experiment 2 , resulting in more accurate placements in the MeAp. The MeAp was targeted because gonadal steroid receptors in the amygdala are distributed primarily in the MeApd (Wood and Newman, 1995; Newman, 1999), and neurons in the MeApd that project to the medial preoptic nucleus also become activated (i.e., Fosimmunoreactive) after ejaculation (Coolen et al., 1998). Lesions of the MeAp are also more disruptive to noncontact erections compared with lesions of the anterior MeA (Kondo et al., 1999). The neurotransmitter content of the MeA-to-MPOA projection neurons is not known. However, in male gerbils, $20 \%$ of the MeApd neurons that were activated by ejaculation were glutamatergic; a similar percentage of MeApd neurons project to the MPOA (Simmons and Yahr, 1999). Therefore, at least some projection neurons may be glutamatergic. In addition, at least some projection neurons from the MeA to the preoptic area make axosomatic contacts with preoptic neurons (Prewitt and Herman, 1998); however, that study did not specify the neurotransmitter content of either the afferent or resident neurons in the preoptic area.

In experiment 2, MeA lesions impaired copulation, such that animals with MeA lesions displayed fewer ejaculations and required more time and more intromissions to reach an ejaculation; in addition, these animals displayed longer PEIs. Compared with experiment 1 , these results are more consistent with previous studies that examined the behavioral effects of MeA lesions (for review, see Meisel and Sachs, 1994). This might be attributed to the smaller and more precise MeA lesions seen in experiment 2 compared with experiment 1 .

Analyses of dialysate samples collected from the MPOA of animals with sham lesions showed increases of extracellular DA in the MPOA during exposure to an estrous female and during copulation, consistent with a previous report (Hull et al., 1995). Analyses of samples from animals with MeA lesions did not reveal such an increase. This finding, coupled with results from experiment 1 , suggests that the impairment of copulation seen after MeA lesions is attributable, at least in part, to a lack of increase in extracellular DA in the MPOA in response to a female and during copulation. Furthermore, it suggests that DA activity in the MPOA is important for the mediation of sexual behavior and that the MPOA DA response during exposure to a receptive female and during copulation is regulated, in part, by inputs from the MeA.

Hull (1995) proposed a biphasic influence of $D_{1}$ and $D_{2}$ families of receptors on copulation and genital reflexes. A relatively low dose of the classic $\mathrm{D}_{1} / \mathrm{D}_{2} \mathrm{DA}$ agonist apomorphine, microinjected into the MPOA, increased the number of erections through activation of $\mathrm{D}_{1}$ receptors, whereas a higher dose facilitated seminal 
emissions through activation of $\mathrm{D}_{2}$ receptors (Hull et al., 1992). Microinjections of a $\mathrm{D}_{1}$ agonist [dihydroxyphenyltetrahydrothienopyridine (THP)] into the MPOA increased the number of erections but inhibited seminal emissions, whereas microinjections of a $\mathrm{D}_{2}$ agonist produced the opposite pattern: decreased erections and increased seminal emissions (Hull et al., 1992). Finally, microinjections of the $D_{1}$ agonist THP facilitated copulation (Markowski et al., 1994), whereas a high dose of the $\mathrm{D}_{2}$ agonist quinelorane (LY-163502) delayed the start and slowed the rate of copulation but also decreased the number of intromissions required to trigger an ejaculation (Hull et al., 1989). Therefore, activation of $\mathrm{D}_{1}$ receptors by moderate levels of MPOA DA may facilitate parasympathetically mediated erections and copulation, whereas intense activation of $\mathrm{D}_{2}$ receptors may shift the autonomic balance to favor sympathetically mediated seminal emission and ejaculation. Thus, both $\mathrm{D}_{1}$ and $\mathrm{D}_{2}$ receptor subtypes contribute to copulation, but the balance may shift during a copulatory bout.

We have shown previously that vehicle-treated castrates that are unable to copulate have very low basal levels of extracellular DA (Du et al., 1998) and no DA increase in response to a female (Hull et al., 1995). The normal basal DA levels in animals with MeA lesions may have been sufficient for copulation to proceed relatively inefficiently but not sufficient to elicit ejaculations readily. This could account for the lower number of ejaculations and the increase in intromissions preceding ejaculation in animals with $\mathrm{MeA}$ lesions. Although the earlier studies with selective $\mathrm{D}_{1}$ and $\mathrm{D}_{2}$ agonists and antagonists used amygdala-intact animals, it seems unlikely that amygdala lesions would dramatically alter the functions of the two receptor subtypes in the MPOA, especially because the mixed agonist apomorphine restored behavior to normal levels in the lesion group, similar to its enhancement of copulation in amygdala-intact animals (Hull et al., 1986; Pehek et al., 1988b; Scaletta and Hull, 1990). Among sham-lesioned animals in experiment 1, apomorphine produced slight, but not statistically significant, increases in intromissions and ejaculations. The lack of statistical significance may have been attributable to the small number of animals in that group $(n=5)$ compared with those in earlier studies $(n=15-25)$.

In summary, the preoptic area and the amygdala play an important role in sexual behavior. The present data confirm the close relationship between extracellular dopamine in the MPOA and copulatory ability in male rats. Furthermore, these data suggest that one means through which the amygdala exerts facilitation of sexual behavior is by increasing DA activity in the MPOA in response to sexually exciting stimuli and during copulation. The presence of a sexually exciting stimulus activates cells in the MeA (Robertson et al., 1991; Baum and Everitt, 1992; Coolen et al., 1996; Heeb and Yahr, 1996; Veening and Coolen, 1998); cells in the MeA in turn project to the bed nucleus of the stria terminalis and the MPOA (for review, see Wood, 1997), in which they lead to an increase in DA release and facilitate copulation.

\section{REFERENCES}

Baum MJ, Everitt BJ (1992) Increased expression of c-fos in the medial preoptic area after mating in male rats: role of afferent inputs from the medial amygdala and midbrain central tegmental field. Neuroscience 50:627-646.

Bitran D, Hull EM (1987) Pharmacological analysis of male rat sexual behavior. Neurosci Biobehav Rev 11:365-389.

Coolen LM, Peters HJ, Veening JG (1996) Fos immunoreactivity in the rat brain following consummatory elements of sexual behavior: a sex comparison. Brain Res 738:67-82.

Coolen LM, Peters HJ, Veening JG (1998) Anatomical interrelationships of the medial preoptic area and other brain regions activated following male sexual behavior: a combined fos and tract-tracing study. J Comp Neurol 397:421-435.

de Jonge FH, Louwerse AL, Ooms MP, Evers P, Endert E, Van de Poll NE (1989) Lesions of the SDN-POA inhibit sexual behavior of male Wistar rats. Brain Res Bull 23:483-492.

de Jonge FH, Oldenburger WP, Louwerse AL, Van de Poll NE (1992) Changes in male copulatory behavior after sexual exciting stimuli: effects of medial amygdala lesions. Physiol Behav 52:327-332.

Du J, Lorrain DS, Hull EM (1998) Castration decreases extracellular, but increases intracellular, dopamine in medial preoptic area of male rats. Brain Res 782:11-17.

Giantonio GW, Lund NL, Gerall AA (1970) Effect of diencephalic and rhinencephalic lesions on the male rat's sexual behavior. J Comp Physiol Psychol 73:38-46.

Harris VS, Sachs BD (1975) Copulatory behavior in male rats following amygdaloid lesions. Brain Res 86:514-518.

Heeb MM, Yahr P (1996) c-Fos immunoreactivity in the sexually dimorphic area of the hypothalamus and related brain regions of male gerbils after exposure to sex-related stimuli or performance of specific sexual behaviors. Neuroscience 72:1049-1071.

Heeb MM, Yahr P (2000) Cell-body lesions of the posterodorsal preoptic nucleus or posterodorsal medial amygdala, but not the parvicellular subparafascicular thalamus, disrupt mating in male gerbils. Physiol Behav 68: 317-331.

Hull EM (1995) Dopaminergic influences on male rat sexual behavior. In: Neurobiological effects of sex steroid hormones (Micevych PE, Hammer Jr RP, eds), pp 234-253. Cambridge, UK: Cambridge UP.

Hull EM, Bitran D, Pehek EA, Warner RK, Band LC, Holmes GM (1986) Dopaminergic control of male sex behavior in rats: effects of an intracerebrally-inf used agonist. Brain Res 370:73-81.

Hull EM, Warner RK, Bazzett TJ, Eaton RC, Thompson JT, Scaletta LL (1989) D2/D1 ratio in the medial preoptic area affects copulation of male rats. J Pharmacol Exp Ther 251:422-427.

Hull EM, Markowski VP, Eaton RC, Lumley LA, Moses J (1992) Opposite influence of $\mathrm{D}_{1}$ and $\mathrm{D}_{2}$ receptors in the medial preoptic area on genital reflexes: implications for copulation. Life Sci 51:1705-1713.

Hull EM, Du J, Lorrain DS, Matuszewich L (1995) Extracellular dopamine in the medial preoptic area: implications for sexual motivation and hormonal control of copulation. J Neurosci 15:7465-7471.

Klaric JS, Hendricks SE (1986) Effects of two-stage lesions of the medial preoptic area on sexual behavior of male rats. Physiol Behav $37: 539-542$.

Kondo Y (1992) Lesions of the medial amygdala produce severe impairment of copulatory behavior in sexually inexperienced male rats. Physiol Behav 51:939-943.

Kondo Y, Yamanouchi K (1995) The possible involvement of the nonstrial pathway of the amygdala in neural control of sexual behavior in male rats. Brain Res Bull 38:37-40.

Kondo Y, Jordan PG, Sachs BD (1999) Small medial amygdala lesions prevent noncontact erection in rats without impairing copulation or partner preference. Soc Neurosci Abstr 25:345.

Kostarczyk EM (1986) The amygdala and male reproductive functions. I. Anatomical and endocrine bases. Neurosci Biobehav Rev 10:67-77.

Liu YC, Salamone JD, Sachs BD (1997) Lesions in medial preoptic area and bed nucleus of stria terminalis: differential effects on copulatory behavior and noncontact erection in male rats. J Neurosci 17:5245-5253.

Malsbury CW (1971) Facilitation of male rat copulatory behavior by electrical stimulation of the medial preoptic area. Physiol Behav 7:797-805.

Markowski VP, Eaton RC, Lumley LA, Moses J, Hull EM (1994) A D1 agonist in the MPOA facilitates copulation in male rats. Pharmacol Biochem Behav 47:483-486.

McGregor A, Herbert J (1992) Differential effects of excitotoxic basolateral and corticomedial lesions of the amygdala on the behavioural and endocrine responses to either sexual or aggression-promoting stimuli in the male rat. Brain Res 574:9-20.

Meisel RL, Sachs BD (1994) The physiology of male sexual behavior. In: The physiology of reproduction (Knobil E, Neill JD, eds), pp 3-105. New York: Raven.

Melis MR, Argiolas A (1995) Dopamine and sexual behavior. Neurosci Biobehav Rev 19:19-38.

Newman SW (1999) The medial extended amygdala in male reproductive behavior. A node in the mammalian social behavior network. Ann NY Acad Sci 877:242-257.

Paredes R, Haller AE, Manero MC, Alvarado R, Agmo A (1990) Medial preoptic area kindling induces sexual behavior in sexually inactive male rats. Brain Res 515:20-26.

Paredes RG, Tzschentke T, Nakach N (1998) Lesions of the medial preoptic area/anterior hypothalamus (MPOA/AH) modify partner preference in male rats. Brain Res 813:1-8.

Paxinos G, Watson C (1998) The rat brain in stereotaxic coordinates. San Diego: Academic.

Pehek EA, Thompson JT, Eaton RC, Bazzett TJ, Hull EM (1988a) 
Apomorphine and haloperidol, but not domperidone, affect penile reflexes in rats. Pharmacol Biochem Behav 31:201-208.

Pehek EA, Warner RK, Bazzett TJ, Bitran D, Band LC, Eaton RC, Hull EM (1988b) Microinjection of cis-flupenthixol, a dopamine antagonist, into the medial preoptic area impairs sexual behavior of male rats. Brain Res 443:70-76.

Pehek EA, Thompson JT, Hull EM (1989) The effects of intracranial administration of the dopamine agonist apomorphine on penile reflexes and seminal emission in the rat. Brain Res 500:325-332.

Pellegrino LJ, Pellegrino AS, Cushman AJ (1979) A stereotaxic atlas of the rat brain. New York: Plenum.

Prewitt CMF, Herman JP (1998) Anatomical interactions between the central amygdaloid nucleus and the hypothalamic paraventricular nucleus of the rat: a dual tract-tracing analysis. J Chem Neuroanat 15:173-185.

Robertson GS, Pfaus JG, Atkinson LJ, Matsumura H, Phillips AG, Fibiger HC (1991) Sexual behavior increases c-fos expression in the forebrain of the male rat. Brain Res 564:352-357.

Rodriguez-Manzo G, Pellicer F, Larsson K, Fernandez-Guasti A (2000) Stimulation of the medical preoptic area facilitates sexual behavior but does not reverse sexual satiation. Behav Neurosci 114:553-560.

Scaletta LL, Hull EM (1990) Systemic or intracranial apomorphine in- creases copulation in long-term castrated male rats. Pharmacol Biochem Behav 37:471-475.

Simmons DA, Yahr P (1999) Neurotransmitters/modulators and connections of cells in the posterodorsal preoptic nucleus (PdPN) and posterodorsal medial amygdala (MeApd) in relation to cells activated with ejaculation in male gerbils. Soc Neurosci Abstr 25:345.

Veening JG, Coolen LM (1998) Neural activation following sexual behavior in the male and female rat brain. Behav Brain Res 92:181-193.

Warner RK, Thompson JT, Markowski VP, Loucks JA, Bazzett TJ, Eaton RC, Hull EM (1991) Microinjection of the dopamine antagonist cis-flupenthixol into the MPOA impairs copulation, penile reflexes and sexual motivation in male rats. Brain Res 540:177-182.

Wood RI (1997) Thinking about networks in the control of male hamster sexual behavior. Horm Behav 32:40-45.

Wood RI, Newman SW (1995) Hormonal influence on neurons of the mating behavior pathway in male hamsters. In: Neurobiological effects of sex steroid hormones (Micevych PE, Hammer Jr RP, eds), pp 3-39. Cambridge, UK: Cambridge UP.

Yamamoto BK, Pehek EA (1990) A neurochemical heterogeneity of the rat striatum as measured by in vivo electrochemistry and microdialysis. Brain Res 506:236-242. 